\title{
A STUDY OF THE RELATIONS BETWEEN CER- TAIN ORGANIC PROCESSES AND CONSCIOUSNESS.
}

\author{
BY PROFESSOR JAMES ROWLAND ANGELL AND HELEN \\ BRADFORD THOMPSON.
}

\section{INTRODUCTORY.}

Circulation and respiration are the organic processes with which this paper is mainly concerned. An inspection of the literature dealing with the relation of these processes to consciousness reveals a condition of disagreement among investigators, both as regards fact and theory. On the side of fact the discrepancies are gradually giving way before more accurate methods of observation and experiment. On the side of theory, however, the progress toward agreement is, perhaps, less noticeable.

The thesis which we shall defend in the following pages is based primarily upon experiments undertaken by us some two years ago with the purpose of determining whether changes in the character of attention were accompanied by any regular alterations in the organic processes above mentioned. The formulation we have reached should, however, if true, be equally applicable to the observations of other investigators. This we believe to be the case, although the description of these observations is often too meager on the psychological side to permit a satisfactory comparison with our own work. Within the bounds of its pretensions our formula, if correct, will have the value of a centralizing, harmonizing principle for a mass of facts which, from many points of view, appear self-contradictory and unintelligible.

At the risk of devoting a disproportionate part of our space to the matter, we shall begin by attempting a sketch of the more important of the relevant facts hitherto observed. So far 
as we are aware, these have never been brought together in the form we adopt, and they furnish the best possible proof of the necessity for some general connective principle.

\section{Historical Outline.}

It will be convenient to state first the factors in the processes under consideration which have been thus far differentiated. ${ }^{2}$

The most striking alterations shown by the respiration consist in changes of rate and depth, or amplitude. The general type of the breathing also displays certain differences under varying conditions. Thus breathing in which costal or thoracic movements predominate may take on a more abdominal or diaphragmatic character. In addition to these changes, however, must be mentioned alterations in the general rhythm and in the duration of the various constituent factors in the total respiratory act. Thus the slight pause which follows expiration may be exaggerated or may practically disappear. Similarly the pause concluding inspiration may be altered in its relation to the total act. $^{2}$ Again, as accompaniments of such changes, we may find the usual relation between the phase of inspiration and that of expiration altered; the normal relation being that of a slight excess of expiration over inspiration. ${ }^{3}$

The more important aspects of the circulation, to which reference is made in this connection, may be summarized as follows: (I) The rate and force of the heart-beat. (2) The tension in the walls of the blood vessels-constriction or dilation. (3) The blood-pressure. (4) The amount of blood sent

'Excellent descriptions and illustrations of apparatus employed in such investigations will be found in ' La Fatigue Intellectuelle,' Binet and Henri, Paris, 1897. The technique of such apparatus has been carefully studied by Hürthle, Pluger's Archiv, 53 ; also by Binet and Courtier, L'Année Psychologigue, 1895. Cf. also Langendorf, Physiologische Graphik.

${ }^{2}$ Certain authorities question the genuineness of these pauses and regard the second as distinctly abnormal. Cf. Landois and Stirling, Physiology, p. 200.

3 The amount of air breathed under various conditions, the amount of oxygen used and the amount of carbon dioxide exhaled have all been studied with much care, but we shall make no reference to these features, as the results attained do not appear to bear in any essentials upon the considerations with which we are here immediately concerned. See Speck, Physiologie des Menschlichen Athmens, Leipzig, 1892 . 
to the brain. (5) The amount of blood sent to the viscera. (6) The amount sent to the periphery. (7) The interrelations between (4), (5) and (6). (8) The features of the cardiac, arterial or capillary pulse: its height or amplitude, shape, etc., with special reference to its anacrotic or catacrotic characteristics. It will of course be understood that in this analysis of salient features in the circulatory process, no implication of complete independence of the elements so distinguished is for an instant contemplated. As a matter of fact, some of the processes do at times vary irrespective of the action of others, but these interrelations will be canvassed more closely later on. ${ }^{2}$

We may summarize the results of the various investigations as follows: The dominant tendency of sensations of every kind is, according to the latest and most careful observations, to produce a vaso-constriction in the periphery and an afflux of blood to the brain. The amount and regularity of these alterations probably depend on the intensity and duration of the stimulus. Those investigators who find regular differences in the organic processes as accompaniments of the algedonic tone of the sensation, would necessarily make an exception in favor of such sensations as are distinctly agreeable and productive in their experiences of peripheral dilations. The effects of sensation upon the heart-beat, the form of the pulse curve and the respiration vary too widely with varying conditions to permit any generalized statement. But wherever a sensation breaks in upon a state of relative quiet and repose, so that a mild emotion or shock is produced, it generally produces acceleration of heart-beat and respiration, the latter being a trifle spasmodic and often deeper.

Mental activity of the type illustrated by application to mathematical computation, memorizing or recalling past experiences is, when contrasted with conditions of greater repose, accompanied by afflux of blood to the brain. Under the conditions of the ordinary laboratory experiment, such psychological pro-

1 Points $(5)$ and $(7)$ concern processes too inadequately investigated to permit very definite formulations.

${ }^{2}$ As in the case of the respiration and for similar reasons, we make no reference to the observations upon the chemical changes attendant on alterations in these various phases of the circulation. Cf. Hermann's Handbuch der Physiologie. 
cesses are sometimes productive of peripheral constrictions and sometimes show peripheral dilations. Their effects upon the form of the pulse curve are equally equivocal, but they result with greater regularity in increasing the rate of both heart-beat and respiration, the latter as a rule becoming more superficial.

Emotions of every sort seem more effective than other psychological processes in producing increase of blood in the brain. Vaso-constriction seems to be by far the most frequent volume change in the periphery, although a modification, similar to that mentioned under the head of sensation, has to be made in favor of those investigators who find opposite physiological expressions for agreeable and disagreeable experiences. The same restriction has to be placed on the statement that acceleration of heart and respiration and increased depth of the latter are accompaniments of all emotions. It is not possible at present to speak definitely of the changes in the form of the pulse curve. ${ }^{1}$

Without injustice to earlier investigators, it may be said that our serious knowledge of the connections between consciousness and the organic processes with which we are here concerned, begins with the classic and revolutionary observations, both clinical and experimental, of the great Italian physiologist, Angelo Mosso.

The results of his investigations may be briefly summarized as follows, bearing in mind that the psychological conditions involved are those of sensation, emotion and application to mental calculations. We may notice first the facts concerning changes in volume:

Psychic activity of every kind produces an increased flow of blood to the brain and a decreased fow to the periphery. ${ }^{2}$ The changes which follow emotional excitements are much more marked than any produced by intellective processes, and the responses to emotional stimuli are more noticeable in the brain than in the periphery. ${ }^{8}$ Sleep is accompanied by a withdrawal of blood from the brain." Deep in-

${ }^{2}$ We shall occupy the remainder of this section with a more detailed statement of the investigations upon which this summary is based

2 Die Temperatur d. Gehirns, p. Iog. Cf. also Patrizi, Riv. musicale ilal., 1896. Some interesting exceptions to this general rule have been observed. They consist of cases in which the activity of attention distinctly antedated the circulatory change. Cf. Die Ermuidung, p. I95.

${ }^{3} \mathrm{Kreislauf}$ d. Blutes im Mensch. Gehirn, p. $72 \mathrm{ft}$.

- Kreislauf d Blutes im Mensch. Gehirn, p. 74 ff. Stimulations which are oo feeble to produce awakening nevertheless result in circulatory alterations of 
spirations produce a decrease of blood in the brain, whereas deep expirations cause an increase. The same thing is noticed in the upper limbs, but in the lower limbs the relations are exactly reversed, a fact which apparently depends upon the inverse pressure relations of the thoracic and abdominal cavities, the walls of the one moving out as the walls of the other move in. ${ }^{1}$ Superficial breathing produces practically no effect upon the cerebral circulation. The plethysmographic changes are not distributed simultaneously over the whole of the body. Local changes of both blood pressure and volume occur. ${ }^{2}$ The changes in the volume of the brain generally precede the changes in the periphery and are, therefore, not to be regarded as on every occasion the mere consequences of such peripheral alterations." The change in the brain is also often observed to outlast the change in the periphery. Moreover, the amount of stuch changes in the volume of blood in the brain is much less than the contemporary changes often occurring in the arm, for example, and of course much less, therefore, than those of both arms together." Added to this is the fact that a decrease in the volume of a limb is not invariably accompanied by an equivalent increase of the brain volume. ${ }^{b}$ The disparity is at times extreme.

Upon the much-mooted point as to whether or no the blood supply of the brain is controlled directly by mechanisms of its own, or indirectly through changes in pressure inaugurated elsewhere in the body, Mosso inclines to a positive opinion in favor of some neural process intrinsic to the brain itself, chiefly on the ground of the apparently primary and independent variations in the cerebral circulation. ${ }^{\circ}$

the brain and periphery. Several observers have confirmed these observations upon the effects of unconscious stimuli. Cf. Binet and Henri, ibid., p. 80 ; also Howell's Physiology of Sleep, Jour. Experimental Med., 1897.

1 Kreislauf d. Blutes, etc., p 133. For following statements see pages 126 and 106. Cf. Marey, Circulation du Sang, for account of changes due to costal or abdominal forms of breathing.

${ }^{2}$ Cf. Bayliss and Starling, Jour. of Physiology, 1894, p. 159.

3 Die Temperatur d. Gehirns, p. 152. Mosso's observations on changes in the blood pressure do not lend themselves readily to a generalized statement. The observations of other investigators to be mentioned later cover the ground more fully, and we therefore make no attempt to epitomize Mosso's work on this point.

- Mays questions the accuracy of these observations. He states, moreover, that he has only succeeded in obtaining noticeable alterations in cerebral circulation in response to emotions, other psychic processes being ineffective. Virchow's Archiv, 1882 .

${ }^{3}$ Die Temperatur d. Gehirns, p. 147.

6 The researches of Roy and Sherrington point to the direct effects, mechanical or chemical, of the metabolisms of the brain as sources, on some occa- 
This is a convenient place to mention Mosso's striking view, confirmed in part by other observers, that the cerebral circulation is after all not the matter of primary import in determining the phenomena of psychic activities. It might naturally be expected that if mere increase of blood to the brain were the essential precondition of intense psychoses, any medium which would produce such increase of blood would be followed by increased mental activity. This is not always the case; witness the effects of amyl nitrite. The activity of the attention and of consciousness in general is rather to be connected with the functioning of ccrtain nerves, which control those activities of the brain cells that are accompanied by psychic events. The appropriate analogy is that of the glands. Just as we find in these organs that mere afflux of blood is insufficient, aside from the action of certain nerves, to produce inception of their secretory functions, so the brain cells require blood for the exercise of their peculiar activities, but the mere presence of blood is not alone an adequate stimulus to such functioning. ${ }^{1}$

Turning now to Mosso's observations on the pulse and the heartbeat, we find the following general principles. With the exception of the rhythm and the height, or amplitude, the peculiarities of the pulse curve are entirely independent of the heart and find their explanation in the changing conditions of the various blood vessels concerned. ${ }^{2}$ The relations between the energy and frequency of the heart-beat are not as yet definitely formulated. The heart-beat is ordinarily slower during sleep than at other times. The pulse becomes anacrotic (Fig. I, A, after Mosso) after phyşical exercise, after heating the vessels and after the inception of complete physical and mental quiet; also as the result of hunger. On the other hand, intellectual activity is accompanied by a catacrotic pulse (Fig. I, B), which is also the form observed after a meal. The anacrotic pulse is not peculiar to the

sions at least, of circulatory control. Journal of Physiology, XI., p. 85. Cf. also Wertheimer, Archives de Physiologie, 1893, p. 297. Gley has shown that in mental activity the flow of blood to the brain is, as Mosso thought, due to other causes than the heart. Étude expérimentale sur l'état du pouls, etc. Paris, $188 x$.

1 Die Ermudung, p. I95 ff Moreover, it does not appear that the brain acts more promptly or more accurately (within the limits of ordinary non-pathological changes of volume) when it is flushed with blood. Patrizi has found the reaction time at the height of undulations in volume very slightly better than that at the lowest point of such oscillations. Cf. Patrizi, Archiv d. Psichiatria, 1896.

${ }^{8}$ Kreislauf d. Blutes, p. 49. 
brain, but is found under certain conditions in other parts of the body. The changes in the form of the brain pulse are noticeable only when vigorous mental activity is contrasted with complete rest. Intense intellective processes are accompanied by increased force of the heartbeat, probably because of the contraction of peripheral vessels necessitating a greater power to propel the blood through them.' Changes in the heart-beat are not always results of changes in the respiration, for they occur independently of such changes."

Apart from the changes already mentioned in connection with the circulation, Mosso's statements about the respiratory accompaniments of psychic processes are somewhat unsatisfactory. In his book on fatigue he says, that observations upon himself show that revery is accompanied by faster breathing than voluntarily directed trains of thought." When one does not attend closely, the diaphragm tends to become quiet and the thorax makes larger but irregular movements. In sleep the diaphragm is probably passive, but periodic changes occur under the effects of drowsiness. In an earlier work, however, he says it is impossible to make any satisfactory classification of breathing types as connected with mental activity, and some of his diagrams certainly conform but poorly to his formulation above quoted. ${ }^{5}$

M. Féré, in his treatise on sensation and movement, gives the first definite statement of antithetical physiological processes as the accompaniments of agreeable and disagreeable experiences respectively. ${ }^{6} \mathrm{He}$ differs from Mosso in finding certain sensory stimulations of emotional tone, which cause dilations of the peripheral vessels, instead of contractions. As is well known, he connects agreeable experiences of vari-

1 These statements may be verified by reference to Kreislauf d. Blutes, etc., pp. 52-58, 114 .

Die Ermuidung, p. 184

${ }^{\top}$ Die Temperatur d. Gehirns, p. 150. There are, however, certain well-recognized changes in the heart-beat, as well as in the blood pressure and volume, which are due to respiration. The beats corresponding to inspiration are somewhat quicker than the others, and the amplitude of the pulse seems somewhat smaller. Binet and Henri (ibid., p. 5o) have called attention to similar rhythmic changes occurring at intervals of three or four respiratory movements.

- Die Ermudung, $p$ I $S_{2}$ ff. The description of the conditions under which these observations were made is too inadequate to permit satisfactory comparison with the work of other investigators.

${ }^{5} \mathrm{Cf}$. Kreislauf d. Blutes, etc., p. $70 \mathrm{ff}$. The irregularities in the breathing which he meets with in mental calculations are probably due to the distinctly abnormal conditions of his subjects.

'Sensation et Mouvement, Paris, I887. He uses the words 'exciting' and 'depressing' instead of agreeable and disagreeable, but his meaning 6eems to be essentially as indicated. 
ous kinds with such dilations of the peripheral blood vessels and with heightened tone of the voluntary muscles. Disagreeable experiences he finds accompanied by the opposite conditions of peripheral constriction and lowered muscular tone. ${ }^{1} \mathrm{He}$ finds momentary intellectual activity accompanied by momentary increase of power in the voluntary muscles. ${ }^{x} \mathrm{His}$ monograph is too inadequate in its statement of details to warrant critical comparison with the more complete investigations now at hand. It has distinct historical importance, however, because its statements, like those of the next author we shall mention, have been somewhat dogmatically incorporated in recent psychological treatises.

A. Lehmann, in his scholarly treatment of feeling, reports with much fullness his observations on the physiological accompaniments of agreeable and disagreeable experiences. ${ }^{3}$ These agree essentially with those of Féré, but emphasize the following facts. ${ }^{*}$ Pleasurable experiences are probably accompanied by increased amplitude of heart movements, disagreeable experiences by decreased amplitude of these movements and ordinarily by dilation of the deep-lying blood vessels. He also emphasizes more explicitly than Féré the deeper and more superficial phases of the breathing which he finds characterizing the two antitheses of feeling.

Probably the most careful, systematic and important experiments, after those of Mosso, are those conducted by Binet in conjunction with Henri, Courtier and Vaschide. However much one may take issue with their usually conservative generalizations-and this is certainly the least convincing part of their work-one cannot abstain from the expression of admiration for the shrewd ingenuity and foresight with which they have executed their tasks. ${ }^{6}$

${ }^{1}$ Cf. ibid., p. 1 1o ff. and p. 7 .

${ }^{2}$ The experiments of Patrizi (quoted by Binet et Henri, loc. cit., p. 194) showed that mental work carried on for an hour weakened the power of the voluntary muscles, unless there was some emotional excitement involved, in which case increased power was observed. In the last case, however, after a time the muscular strength fell below the normal.

${ }^{3}$ Hauptgesetze d. Mensch. Gefuhlslebens, translated by Bendixen, Leipzig, 1892.

Ibid., p. $82 \mathrm{ff}$.

5Lehmann's results, which were obtained by experiments upon five persons, certainly require confirmation. Like Férés, they differ in the manner pointed out above from the results of Mosso, and they are distinctly at variance with many results obtained by recent investigators, not to mention our own.

${ }^{6}$ It will be convenient to refer in connection with these authors to a certain amount of the recent monograph literature, much of which is canvassed by them. 
They find that vaso-constriction of the peripheral blood vessels is the usual result of psychic activity of any sort, especially when this follows relatively greater quiet. ${ }^{1}$ There does not seem to be any constant and demonstrable relation between agreeable and disagreeable experiences on the psychic side and vaso-dilation and constriction on the physiological side. Pain has been observed to cause a dilation under certain peculiar conditions, and moderate pleasure has on several occasions been accompanied by constrictions. ${ }^{2}$ The true psychic opposites from this point of view seem to be repose and activity with varying degrees of physiological excitation as their counterparts. ${ }^{3}$ When attention is vigorously fixed on a calculation, for example, there is sometimes a dilation, whose nature is not known, and sometimes a constriction of greater or less duration."

1 This agrees with Mosso. See above.

'Binet et Courtier, L'Année Psychologiquc, I897, p. 87 ff., also p. I26; Binet et Henri, ibid., p. 92.

Cf. also Patrizi, ibid. Rivista di Freniatria, etc., 1897 . We know these articles only from reports.

Shields finds vaso-constriction of periphery with both agreeable and disagreeable odors-Journal of Experimental Medicine, 1896.

Dumas, Revue Philosophique, i 896, also 1897 . Dumas' investigations with morbid and insane cases confirm in general the antithetical relations formulated by Lehmann and others regarding joy and sadness and the physiological exexpressions of dilation, constriction, etc.; adding some interesting observations on the changing number of blood corpuscles under these conditions. He meets curious exceptions, however.

Sewall and Sanford, studying changes of volume in the forearm under various forms of electrical, mechanical and thermal stimulation, found that strong stimulations generally produced constriction, whereas weak stimulations gave slight dilations after transitory constrictions-Journal of Physiology, XI., p. I79 ff.

3The very interesting experiments of Howell on sleep, already referred to, furnish beautiful supplements to Mosso's observations, and show that in normal sleep there is first a rapid decrease of blood in the brain, owing to fall in arterial pressure (chiefly in the periphery, it appears) with flooding of the peripheral vessels. This is followed by a period of relative quiet, and then the pressure gradually rises, the peripheral vessels undergo constriction and finally awakening occurs. He regards the fatigue of the vaso-motor mechanism as the inımediate cause of sleep. He is inclined to disagree with Mosso concerning an independent vaso-motor mechanism of the brain.

- MacDougall, in his article on the Physical Characteristics of Attention (Psychol. Review, 3-158), practically agrees with the French observers, of whom we are writing, as regards the volume changes bere referred to. Under the head of 'pulse and volume changes' appearing when attention is focussed on a continuous sensory stimulus, he omits any definite reference to the second part of his paragraph title, so we cannot record his results. With what he calls 
Short, intense mental application-e. $g .$, the solution of a mathematical problem extending over three or four minutes-almost invariably increases the rate of the heart-beat. ${ }^{2}$ After the cessation of the work, this acceleration may continue, or there may be a reaction toward a rate slower than the original one. The effects of long mental effort are less well known, but there seems to be an increased tendency toward slowing of the heart-beat, when compared with the natural tendency to retardation during the later hours of the day and in general under increasing fatigue. ${ }^{2}$ Emotions of every kind, practically without exception, produce increase in the rate of the heart-beat. A few rare cases of pain and sadness have been observed to produce a gentle slowing of the rate. In general the changes observed, not only on the heart, but also on the other organic processes under consideration, show much more dependence upon the intensity of the emotion or affective condition than upon the quality as agreeable or disagreeable."

'perceptual attention' he obtains first constrictions and then periodic fluctuations of dilations and constrictions. These undulations appear under several of the conditions he has studied, e.g., attention to calculations, recalling of past experiences, and continued sense impressions.

${ }^{1}$ This has been noticed by a number of investigators, Cf. La Fatigue Intellectuelle, p. $4^{1} \mathrm{ff}$. Mentz (Plitl. Studien, XI., p. $5^{67} \mathrm{ff}$.) reports a quickening of the pulse which seems closely related in its rate to the difficulty of the task undertaken.

Moderate physical exercise generally increases the rate and force of the heart-beat, but where excessive a contrary effect may be produced. The changes under physical exercise are, perhaps, due more immediately to alterations of blood pressure, which Marey has shown may by merely mechanical means affect the rate of the heart. In mental activity the pressure seems to rise, and as this alone should, on the grounds of merely mechanical explanations, decrease the rate, it is probable we have here a direct nervous control. Cf. La Fatigue Intell., p. 37 ff. and 58 . Mentz finds (Cf. ibid., pp. $3_{3}, 95$, IOr) that auditory stimuli, whether noises or tones, produce at first slowing of the pulse and then a gradual quickening. Changes in intensity sho:v the same result, the quickening beginning at the point where the stimulus becomes disagreeable. With involuntary attention acoustic stimuli were found to produce slowing, with voluntary attention quickening of the pulse. MacDougall (ibid., pp. 163, 169) obtained, with voluntary perceptual attention, increase of heart rate, with continuous sensory stimuli (tracing of figures on the face) slowing. The cases of retardation in the heart-beat reported by both these investigators seem to lend themselves with difficulty to harmonious incorporation in the observations and hypotheses of Binet and his fellow workers. They agree with our own observations, however.

2 The capillary pulse may almost disappear under these conditions. It has been suggested that this is due to increased pressure. If true, this fact would seem'to present a rather troublesome anomaly for Howell's interesting theory of sleep, elsewhere referred to. Cf. Binet et Henri, loc. cit., p. $96 \mathrm{ff}$.

'Binet et Courtier, L'Année Psychologique, I897, pp. 104, 125-126. 
Mental work when intense shows a tendency to alter the form of the capillary pulse curve by decreasing its amplitude and with some persons rendering its angles blunter, while the dicrotic may move upward or shrink. With others there is instead of this a distinct emphasizing of the dicrotic and no noticeable decrease in angularity. ${ }^{1}$ Conditions of quiet and repose are ordinarily accompanied by a pulse of large amplitude with clear dicrotic. It is possible that a classification of the emotions may prove to be feasible on the basis of the changes of the pulse, but this is hypothetical.

The blood pressure probably rises under every mental excitation, whether the occasion be attention to a sensation, to a calculation or to an emotion. 2 Nor does the nature of the emotion apparently affect the fact of this rise, although it may show a difference in the degree of the latter.

The rate of respiration is increased by mental work of every kind, both the expiration and the expiratory pause being shortened, emotions producing an increased amplitude in the respiratory curve, mental calculations and the like producing more superficial breathing, with decrease of amplitude in the curve. Occasionally sadness produces a slowing of respiration. ${ }^{3}$ The effects of emotional states are, however, relatively irregular.

${ }^{1}$ Gley (ibid ) finds mental work increases the amplitude of the carotid pulse and accentuates the dicrotic. Binet et Henri (ibid.), p. $98 \mathrm{ff}$, also 113 and 120 ff. Binet et Courtier (ibid), pp. 30-65. Physical exercise of a violent type seems to lessen the amplitude of the pulse and to diminish the clearness of the dicrotic.

'Kiesow's observation (Philos. Studien, 1895) that changes in blood pressure are noticeable only in connection with affective psychic conditions is criticised on the ground of inadequate technique.

${ }^{3}$ Binet et Henri, ibid., p. 156 ff. B1net et Courtier, ibid., p. 65.

Delabarre (Reune Philosophique, Vol. XXXIIr., p. 639 ff.) found that persons who naturally breathe rapidly show relatively little effect on their respiration when their attention is engaged; but persons who ordinarily breathe slowly display a distinct teudency to acceleration of respiration when exercising their attention, the acceleration seeming to bear a general relation to the measure in which the attention is exercised.

MacDougall (ibid.) found that with perceptual and sensory attention there are generally increased rapidity aud superficiality of respiration. The long inspiration and short expiration of sleep and relaxed inattention give way to lengthening of the time occupied by the second factor and shortening of the time of the first. The effects on the respiratory pause are ambiguous. Calculation produces the same general changes found by the French investigators. Recall of past events, when tinged with emotional excitation, is productive of great irregularity of amplitude and form, although the increase of rate is still observed. 
Like ourselves, these investigators have been relatively less interested in the effects of psychological conditions upon the voluntary muscles. Mental activity certainly affects the muscles, but the effects differ, depending on the length of time devoted to the psychic process and on the presence or absence of an emotional tone in the experience. ${ }^{1}$

\section{Theoretical Considerations. ${ }^{2}$}

It will be observed that the investigations which we have been reviewing deal with two separate problems. The first problem concerns the differences in circulation, respiration and muscular tone which characterize the antithetical affective conditions denominated respectively agreeable and disagreeable. The second has to do with the differences manifested by these physiological activities under the various typical psychological conditions, e. g., sensation, intellection, etc., and more especially with the differences distinguishing the affective from the non-affective processes. It is unnecessary to emphasize the lack of any established general principle of correlation for the results of these various investigations, much less to dwell upon the disagreements in regard to details.

Mentz (ibid.). In general the breathing tends to follow the rate of the pulse reported above. The strong tendency of heart and respiration to change rate together and in the same direction has been noticed repeatedly. The intimate nature of the connection is unknown.

Lehmann's interesting observations (Philos. Studien, Vol. IX., p. 66) on the fluctuations of attention and the different phases of respiration seem to show that the moment of completed inspiration, when the volume and pressure of the blood in the brain are at a maximum, is most favorable for mental activily. Needless to say, this does not altogether agree with Patrizi's observations.

in. Whipple has found (Amer. Jour. of Psychology, r898, p. 560) that forced respiration seems to assist muscular activities, but to interfere with psychic processes and the functions of the higher centers.

${ }^{2}$ Jastrow (Amer. Jour. of Psychol., IV., 398 ; V., 223) and Tucker (Amer. Journal of Psychol., VIII., 394) have studied the nature and direction of certain unconscious movements of the voluntary muscles connected with different psychological processes. Heinrich (Zeits. für Psychol. und Physiol. d. Sinnesorgane, IX., 342 ; XI., 410 ) and Mentz (ibid.) have found that with mental calculations the pupils dilate, the lenses become flat and the eyes assume nearly parallel axes.

'Logically and chronologically, Section IV. of the paper dealing with our own experiments should precede Section III, for the views defended here are based on the observations therein reported. The present orderis adopted in the interests of brevity and clearness in presentation. 
If we knew the precise significance in terms of organic metabolisms of such processes as constriction and dilation, we might hope to build up a theory on the basis of such knowledge. Unfortunately, this is not the case. Furthermore, we have seen that various observers have failed to note any uniform connection of these processes with pleasure and pain, in which conditions the 'vitality' theories would find the reflection of organic weal and woe. We find ourselves thrown back then upon some general view of the organism as a whole, if we desire a principle of interpretation for the phenomena concerned.

Such a view is offered us by the ordinary evolutionary doctrine, which finds the essential problem of the organism in the adapting of itself to an environment. This adaptation must involve on its physiological side metabolisms of various kinds, in which katabolisms and anabolisms must sustain certain fairly definite relations of dynamic equilibrium, provided the life process is to be subserved.

If we make reference to any one region or to any one process, the exact relations of these antithetic metabolisms must be constantly changing. Slight excesses of wastage at one point and one period will be offset by repair at a later period. The variations from equilibrium must in conditions of health be relatively insignificant, in order to permit of elastic response to the demands of the total environment. Moreover, these adaptive processes must be constantly in progress and must accompany the psychological conditions called intellective quite as truly as those called affective. Having regard, therefore, to the very various circumstances in which the organism is called upon to respond to changing stimulations, it seems at least possible that the regularity with which these metabolic processes progress, rather than the presence or absence of any one feature in the process, should be the most characteristic expression of the total organic condition. Certainly the presumption that a psychological process like pleasure in its multiform phases should, regardless of its concomitant mental conditions, be accompanied invariably by a single physiological process like dilation, implies a simplicity of structure and function in the psycho-physical organism and a constancy of organic and environmental conditions which probably do not exist. 
In view of such considerations our experimental observations lead us to believe that the changes in circulation and respiration which accompany alterations of consciousness can be formulated in terms of attention as follows:

When the attentive process runs smoothly and uninterruptedly, these bodily activities progress with rhythmic regularity. ${ }^{1}$ Relatively tense, strained attention is generally characterized by more vigorous bodily accompaniments than is low-level, gentle and relatively relaxed attention (of drowsiness, for instance); but both agree, so long as their progress is free and unimpeded, in relative regularity of bodily functions. Breaks, shocks and mal-coördinations of attention are accompanied by sudden, spasmodic changes and irregularities in bodily processes, the amount and violence of such changes being roughly proportional to the intensity of the experience. ${ }^{2}$

In order to make clear the application of this hypothesis to the facts at issue, we must analyze briefly the mental conditions concerned with reference to the attention. We shall need to consider the following: (I) Emotions of various kinds. Sensations both feeble and intense, both expected and unexpected, both transitory and continuous, both agreeable and disagreeable. (3) Intellective processes involving memorizing, recalling and reasoning in the narrow sense, e.g., mathematical calculations; also revery.

Now, emotions represent psychological conditions of great instability. Especially is this true when the emotion is profound. The necessity is suddenly thrown upon the organism of react-

1 To prevent tedious repetition we shall hereafter, except when otherwise stated, use the phrases 'bodily activities,' 'bodily processes,' 'functions,' etc., to mean respiration and circulation.

2 It will be remembered that the fundamental antithesis found by Binet and his co-workers is that of mental activity in general as against mental passivity. In apparently abandoning any one physiological change like vaso-constriction or increased rate of respiration as a criterion of the psychological condition, we do not mean to imply, even tacitly, that no single change of such character is an essentially constant companion of any one psychological process, like the emotion of anger, for instance. We simply emphasize the apparent absence of any such change as an invariable index of more than one or two conditions, whereas the changes as we formulate them appear to be constant for all conditions. The experimental portion of the paper will bring this point out more fully. 
ing to a situation with which it is at the moment able to cope only imperfectly, if at all. The condition is one in which normal, uninterrupted, coördinated movements are for a time checked and thrown out of gear. ${ }^{1}$ Equally spasmodic and interrupted is the activity of attention. It may on the other hand be asserted, in opposition to this view, that never is attention so monopolized and completely absorbed by a situation as in the case of a deep emotion. But this is to overlook the cataclysmic change at the outset of the emotion, as well as the violently recurrent rhythms with which the situation is surveyed. ${ }^{2}$ In no strict sense does the attention ever delay long with absolutely one phase of an idea, ${ }^{3}$ and by so much as the profound emotions are more intense than the ordinary experiences of life, by so much are the shifts in attention more violent than usual.

Moreover, affective conditions of every kind show their affinity with the emotions by a similar instability of attention. This instability is far less with agreeable experiences than with disagreeable ones. This may be connected with the fact, made much of by some psychologists, that pleasure represents a tendency to persist and pain a tendency to change." It calls to mind also the theories of pleasure as associated with normal and moderate activities, and pain as associated with excessive activities. ${ }^{5}$ But whenever the experiences are very intense we meet,

${ }^{1}$ Cf. Dewey, 'Theory of the Emotions,' Psychological Review, Vols. 1 . and II.

${ }^{2}$ It may at first sight appear that, however fairly this description applies to the more tempestuous emotions, like anger, it is seriously defective when applied to some of the semi-morbid phases of grief and depression. Waiving the justice of the criticism of this characterization of the play of attention in the depressive emotions (we think the apparent difference of opinion rests on a confusion of attention to a topic of thought with attention to a single image), we may simply reiterate, that our observations indicate that the bodily changes run parallel, as regards their regularity or irregularity, with the mode in which attention proceeds. In general the emotions show a much disturbed condition in this particular. But for us this is more or less of an accident, and our contention would be in no wise affected if emotions showed a precisely contrary condition, provided attention also changed its characteristics.

${ }^{3}$ Cr. James, Prin. of Psy., Vol. I., p. 421. Ribot's Psychol. of Attention presents a thoroughgoing account of attention as 'monoideism.' The effects of neural fatigue would forbid any long-continued dwelling upon literally one idea. Cf. Hylan, 'Attention,' Monograph, PsychoL. Review, 1897.

- Stephen, Science of Ethics. Horwicz, Psychol. Analysen.

${ }^{5}$ Spencer, Prin. of Psychology. 
at the moment of their initiation at least, with relative instability of attention, though the continuance of this instability is incomparably more marked with the unpleasant states than with the pleasant ones. ${ }^{1}$ This is tantamount, of course, to saying that the whole distinction is relative.

The different conditions of attention under which sensations may be experienced vary rather more widely than those of emotions, so that if we had regard only to the fact of the presence of a sensation, we might fallaciously assume a uniformity of conditions which does not exist. What we have said of affective conditions in general, in the previous paragraph, holds equally true when these affective experiences have a sensation as their basis, and need not be repeated here.

The distinction between expected and unexpected transitory sensations is one of considerable import for our interpretation. ${ }^{2}$ This is the more true the more powerful the sensory stimulus employed. It becomes relatively insignificant as such stimuli approach the limen. The effect of an expected sensation upon attention will, if the sensation be not so intense as to produce shock, nor so feeble as to require excessive effort to detect it, be the securing of a slight strain of anticipation, with at times a somewhat definite relaxation when the sensation is felt. On the whole the play of attention is relatively free and unimpeded. When the stimulus is so faint as to require great concentration we may get more irregularities, owing to the fluctuations of attention from fatigue, distraction, etc. But still the conditions are relatively stable. With the very intense stimulus, whether expected or not, there is sure to be something approaching shock, and with this the introduction of a distinctly disagreeable affec-

'Ward's formulation of pleasure and pain in terms of the effectireness of attention has much that is allied with the view we are presenting. It does not, however, seem to do full justice to the neutral-toned consciousness of moderate intellectual labor, where attention is apparently exercised with distinct effectiveness. (Cf. Ency. Brit., article 'Psychology.')

2 The conditions involved in expected and unexpected sensations approximate closely those of voluntary and involuntary sensory attention (cf. Mentz, ibid.). The so-called cases of involuntary sensory attention are such as occur when a stimulus succeeds in breaking in upon a condition of mental pre-occapation, whether one be engaged in intense thought processes or in some of the various forms of revery. We cover both these cases, but do not use this terminology. 
tive condition, whose consequences we have already canvassed. Indeed, a sensory stimulus of very moderate intensity may, if unexpected, produce this shock in a rudimentary way, and this more violent disturbance to attention is the principal difference noticed between the expected and the unexpected sensation. With many unexpected sensations this shock may practically disappear. The process going on at the time the stimulus is given will determine in large measure its effectiveness or ineffectiveness in producing such shock.

Sensations which are continuous, provided they be not very intense, produce conditions of attention which are relatively regular and stable. We speak here of the cases in which attention is intentionally fixed on the sensations. If continued long, we shall get rather definite fluctuations of attention, but these need not be violent within any ordinary limit of time. Sooner or later we should meet total collapse of attention, preceded by the phenomena of mal-coördination that accompany fatigue. Continuous sensations, which are not made definite objects of attention, produce very various results, sometimes being relatively ineffective and at other times seeming to modify materially the attentive process. The psychological conditions involved appear too ambiguous to warrant laying much stress on these cases. ${ }^{1}$ A series of very intense sensations, or a really continuous sensation of this kind, will produce, as in the case of the transitory sensation, distinct shock and its disturbing consequences for attention.

From the standpoint of attention the intellective processes involved in memorizing and in simple mathematical calculations have much of affinity with the continuous sensation and represent relative stability and regularity. If the task becomes too confused, as it may when one is required to multiply mentally one three-place number by another, then we may meet with breaks and irregularities in attention. Moreover, we shall often find that such experiences are accompanied by a slight feeling of anxiety and distress, springing from the interest in accom-

${ }^{1} \mathrm{Cf}$. Mentz (ibid.). The chief difficulty in these instances arises from attempting to apportion the responsibility for the cbanges observed between the existing mental processes, into which the continuous sensation is supposed at times to inject itself, and the sensation itself. 
plishing the work promptly and correctly. Where this element enters to any degree, we may look for the characteristics of emotion. Indeed, we may properly remark in this connection that under ordinary conditions these processes, which we are analyzing separately, necessarily overlap one another at times. The mental application in the case of the intellective processes is usually to problems received from sensory sources, visual, auditory, etc. The sensations impinge upon already existing affective and intellective conditions, and emotions are, with the best of intentions on the part of the experimenters and subjects, likely to intrude themselves in some measure upon all the processes studied. When the attention is relatively strained and tense, we meet the greatest stability and regularity, if the task in hand is just difficult enough to be successfully carried forward at the rate at which new aspects of it open up. Thus we may obtain great regularity of functioning, if series of problems in addition or multiplication are presented at just that rate which permits their most rapid solution, avoiding on the one hand unoccupied leisure between the problems, and on the other hand insufficient time for completing them.

The cases in which one attempts to recall past events show considerable variations, depending on the nature of the subjectmatter recalled. Verbal material which has been learned by heart may be recalled under conditions of great stability and regularity of attention. Events, on the other hand, may or may not be recalled readily, and if they do not come to mind easily we shall get more or less instability of attention, the results depending on the amount of effort put forth. Such processes are especially prone to take on emotional coloring with its tendency to instability.

Revery, in the proper sense of the word, represents frequently a high degree of free and regular play of attention, interrupted now and then by the emotional suggestiveness of the subject of thought. When revery passes over into drowsiness, the attention becomes much relaxed and functions on a low level of intensity, but yet as a rule with a considerable degree of smoothness. Individuals vary vastly, however, in the nature of the revery process. 
If we turn now and arrange our psychological conditions in a hierarchy representing increasing stability of attention, we shall obtain something of this kind: (I) The profound emotions, presenting sometimes an appearance of stability, but even here distinctly of the abnormal, paralytic type. (2) The more violent affective conditions, certainly the disagreeable and painful experiences, less confidently the instances of extremely pleasurable experiences. (As has often been mentioned, it is exceedingly difficult to produce very intense pleasures under laboratory conditions.) (3) Cases of transitory and relatively superficial emotions (including cases in which emotional excitement occurs, although the conditions are ostensibly those of intellective processes, e. $g$., recall of past events) intermingled with responses to unexpected sensory stimuli of moderate intensity and brief duration. Expected sensations, if relatively intense, also belong in this class, together with many agreeable sensory experiences. (4) Cases of continuous sensations, the regularity being greater in proportion to the effort made to attend and being: perhaps, greatest with relatively weak sensations. Mental application, as in the case of mathematical calculations, when executed under the most favorable conditions as above described. Many cases of non-emotional revery. The revery of drowsiness differs in its type of regularity from that manifested by application to a problem, in that one is accompanied by the phenomena of relaxation and the other by those of greater organic excitation. But both are relatively stable. ${ }^{1}$

This brings us to a consideration of our experimental material. After a brief description of the conditions under which we have worked, apparatus, etc., we shall proceed to show how radically the physiological accompaniments of apparently similar psychological conditions may vary from time to time, depending on the manner in which attention functions. It should

'It will be understood that this classification pretends to nothing but a rough suggestiveness of the relations these different processes bear to one another when attention is employed in this way for connecting them. It will have served its purpose if it brings out a few salient relationships, such, for cxample, as the community of certain sensation processes with intellective conditions and that of certain other sensation processes with emotion. 
not be understood that we dogmatically deny any constancy of changes aside from the form of constancy we emphasize, although such constant conditions are rare. We simply maintain that from our observations the only feature which appears essentially constant under ALL PSYCHOLOGICAL conditions is the relative stability and instability (of the dynamic type) which these organic activities manifest in connection with the different processes of attention. We have stated this previously, but repeat it to avoid confusion and misunderstanding.

\section{Report of Experiments.}

The experiments which give rise to this paper consist of two very complete series of tests taken from two different subjects. Less extended observations upon a number of other subjects have tended to confirm our confidence in the general position we adopt.

The curves showing circulatory changes are all capillary pulse tracings, taken with the air plethysmograph invented by Hallion and Comte. The air plethysmograph was adopted in preference to the water plethysmograph, cardiograph, or any of the methods of taking the arterial pulse directly, because of the greater delicacy and accuracy with which it registers slight variations in the form and amplitude of the pulse curve. The plethysmograph was connected with a Marey tambour, writing in the ordinary manner upon a smoked drum. After a somewhat extended series of experiments upon technique, the most advantageous bodily position, adjustment of the plethysmograph, quality of rubber and length of pointer for the tambour and relative position of tambour and drum were adopted and preserved throughout the experiments. ${ }^{1}$ Careful tests upon the accuracy of the instruments have convinced us that the curves may be relied upon for recording the direction of changes in the volume of the blood in the hand, in the rate of the heartbeat, and in the form and amplitude of the capillary pulse. ${ }^{2}$

1 The conditions adopted by us agree substantially with those of Binet and his co-workers. The fact that a few of our curves are to be read in a different direction from the others arises from a temporary reversal of the drum, which has no effect whatever on the curves, although we regret the lack of uniformity in their appearance.

\& The apparatus does not record pressure changes. 
'Plate' I.

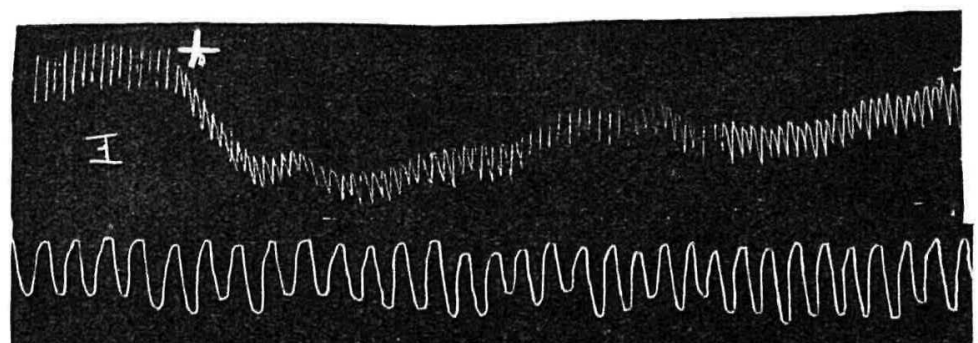

B

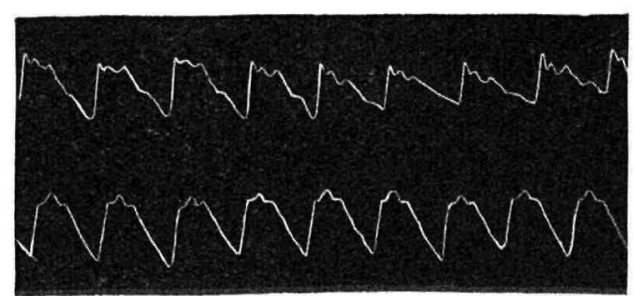

Whathwhwhthe Whuphorom

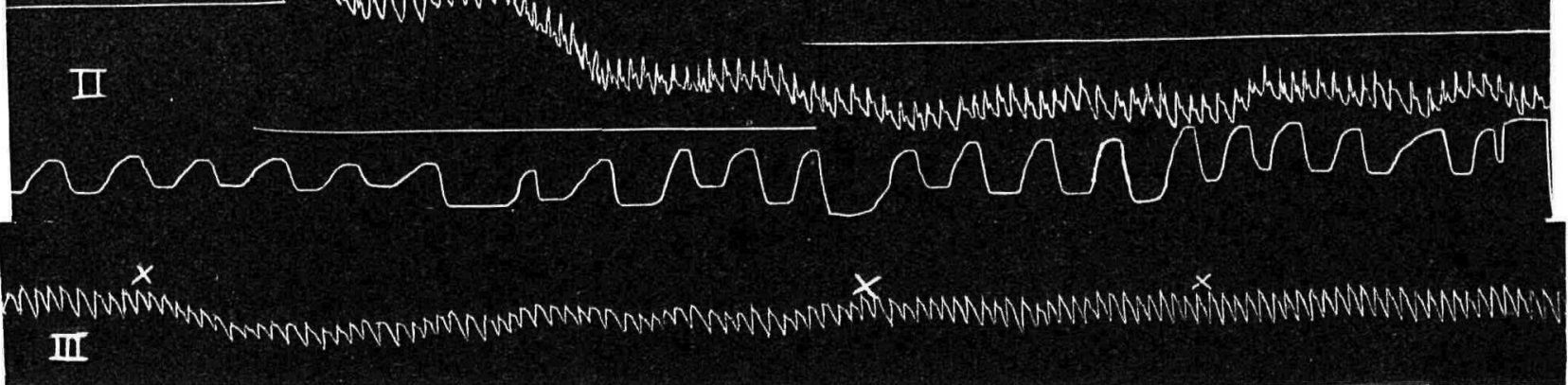

I., Anger; II., Emotional Excitement; III., Cross I, Embarrassment ; 2, Addition ; 3, Multiplication. EXPLANATION OF CUTS.

I. All curves read from left to right, except when arrows indicate the contrary. 2. The process illustrated by the curves begins in every case at the point indicated by a cross. 3. A fall in the pulse curve always indicates vaso-constriction, and a rise vaso-dilation. 4. The respiratory curves, when given, are always placed immediately under the pulse curves with which they belong. 
The absolute measurements of the curves of one day could not, however, be compared with those of another, since slight changes in the adjustment of the plethysmograph or of the tambour produce slight alterations in the absolute dimensions of the curves. $^{1}$ A modified form of Bert's respirator was used for recording the breathing curves.

The emotional experiences of this series of experiments were spontaneous emotions arising from the subject's own thoughts when left to himself. The most noticeable effects of emotional states upon the bodily processes are the sudden, violent changes and irregularities produced. The vaso-motor shifts are the most evident of these changes, although marked irregularities in the rate and amplitude of both breathing and pulse curves occur. In Plate I., Figs. I. and II. show characteristic cases of violent emotion; Fig. III. is an example of one of the milder emotions, embarrassment.

It is in the case of the emotions, where the agreeable and disagreeable experiences are most intense, that we should expect to find the most marked and constant correspondence of agreeable states with one set of physiological processes and of disagreeable states with an antithetical set, if any such relationship existed. But our curves show not the slightest evidence of such an interconnection. None of the various factors involved, vaso-motor level, rate and amplitude of the pulse curve, position and emphasis of the dicrotic notch, or rate and amplitude of the breathing, changes uniformly in one direction for agreeable experiences, and in the opposite direction for disagreeable experiences. No doubt cases occasionally occur where some regular connection of the kind mentioned is found. But it is occasional and not invariable, in fact probably rare. Almost all of our emotional experiences, whether agreeable or disagreeable, produced vaso-constrictions. This agrees with the observations at the Sorbonne and is what Mosso's work would lead us to expect. Figs. IV. and V. (Plate II.) are examples of an unpleasant and a pleasant anticipation respectively, experienced

1 Binet expresses a greater confidence in the comparability of curves taken at different sittings than our experience has led us to feel. But, as the matter is largely one of skill, be is doubtless justified in his assurance. 


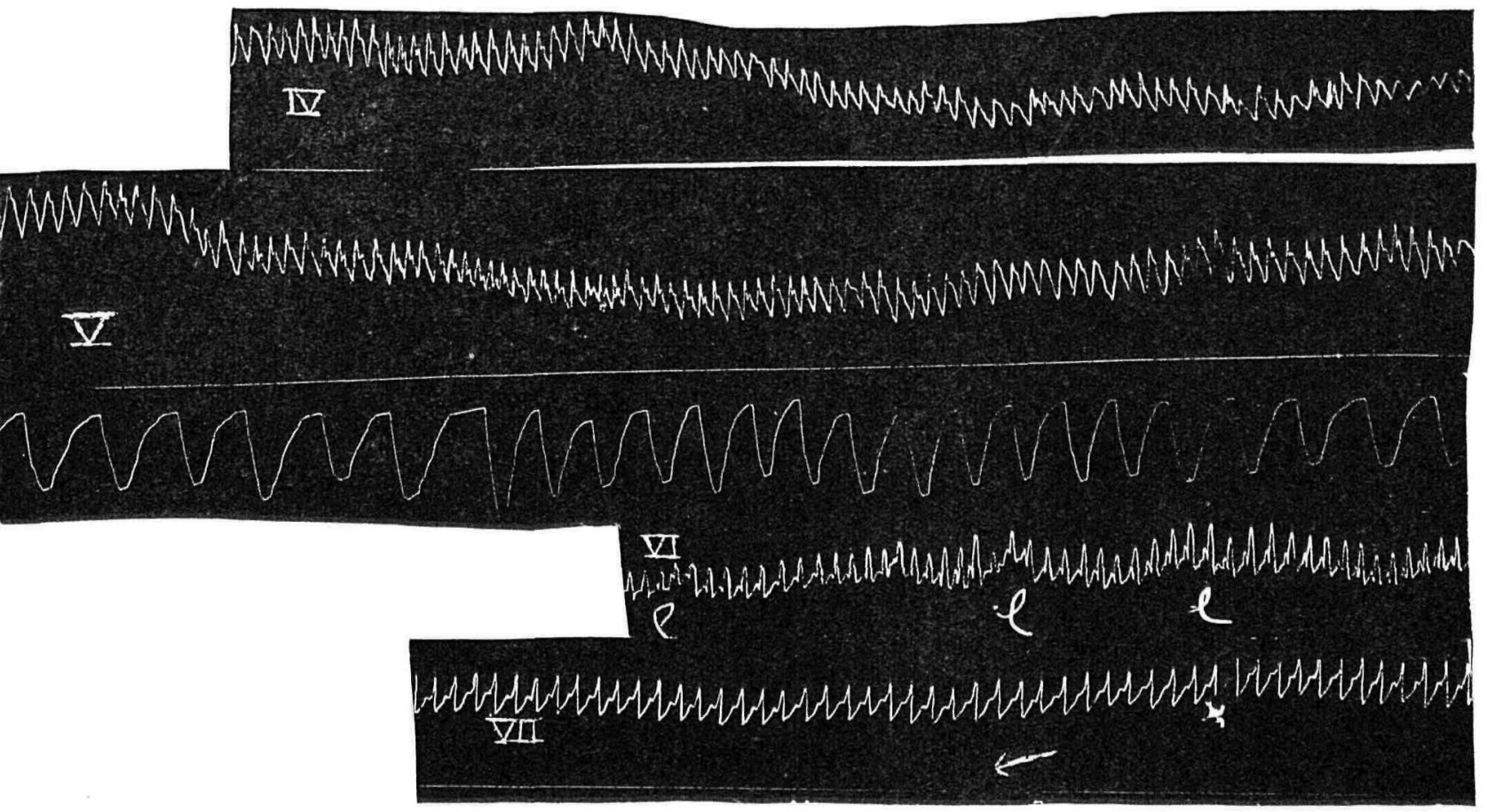


by the same subject at one sitting. Both cause violent vaso-constrictions. The most important exception to this rule is the fact that with one of the subjects, laughter causes a slight, sudden vaso-dilation (see Fig. VI., Plate II.).

At first sight the vaso-dilations due to laughter would seem to be a confirmation of the theory that agreeable experiences are accompanied by dilations of the peripheral blood vessels. But there are several facts which take away the value of this evidence. In the first place, the vaso-motor change seems to be a secondary effect of the sudden spasmodic change in the breathing. Of course, the spasmodic breathing of laughter is an essential factor in it, and it is impossible to separate the secondary vaso-motor changes due to breathing from those accompanying the feeling of amusement in laughter. But the character of the vaso-dilations seems to run parallel with the breathing changes rather than with the feeling of amusement, which does not, as every one knows, always correspond with the heartiness of the laughter. A hearty laugh, causing sudden, violent changes in the breathing curve, is accompanied by the sharpest and most marked vaso-dilation, while a smile or mild laughter causes much slighter and more gentle changes in the vaso-motor curve. In confirmation of this view, we have one curve from this same subject, in which mere feeling of amusement, unaccompanied by any of the breathing changes of laughter, produced a slow vaso-constriction (VII., Plate II.). But more important still, as contrary evidence, is the fact that, in the case of the other subject, constriction and not dilation is the most marked vasomotor accompaniment of laughter. VIII., Plate III., shows characteristic laughter curves for this subject. They display slight initial dilations followed by marked constrictions. In this case, too, the amount of the vaso-motor change is in general proportional to the amount of the disturbance in the breathing. But why in one subject spasmodic breathing should have vaso-dilation as its concomitant, and in another subject vaso-constriction, is a mystery. However, the facts show that the dilations of laughter in this case can not be taken as confirming the theory that vaso-dilation accompanies pleasant experiences.

The amplitude of the pulse curve shows a greater or less 


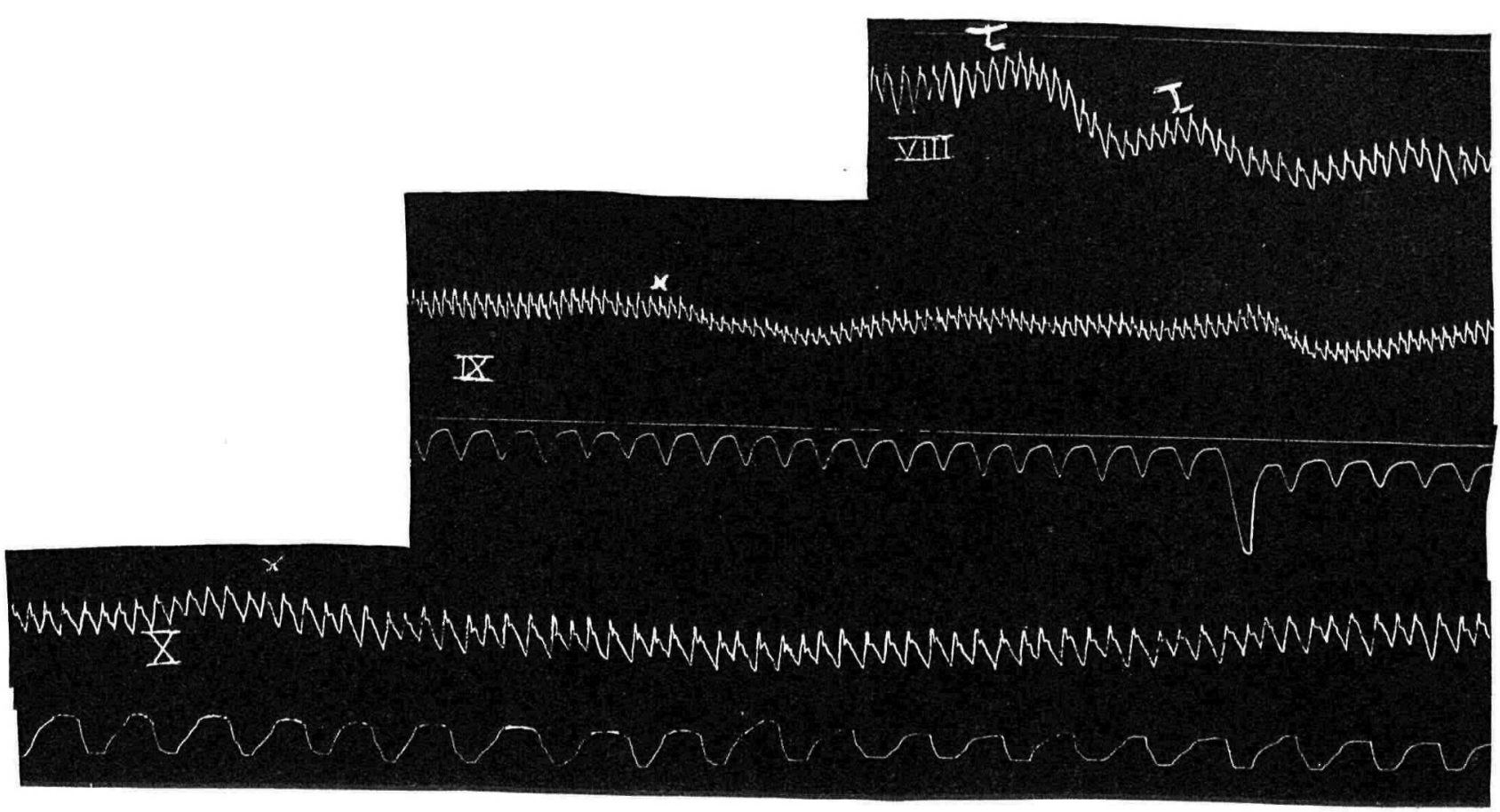

VIII., Laughter marked 'L'; IX., Interest followed by Emotional Excitement at Cross; X., Apprehension, warned of impending shock. 
Plate IV.
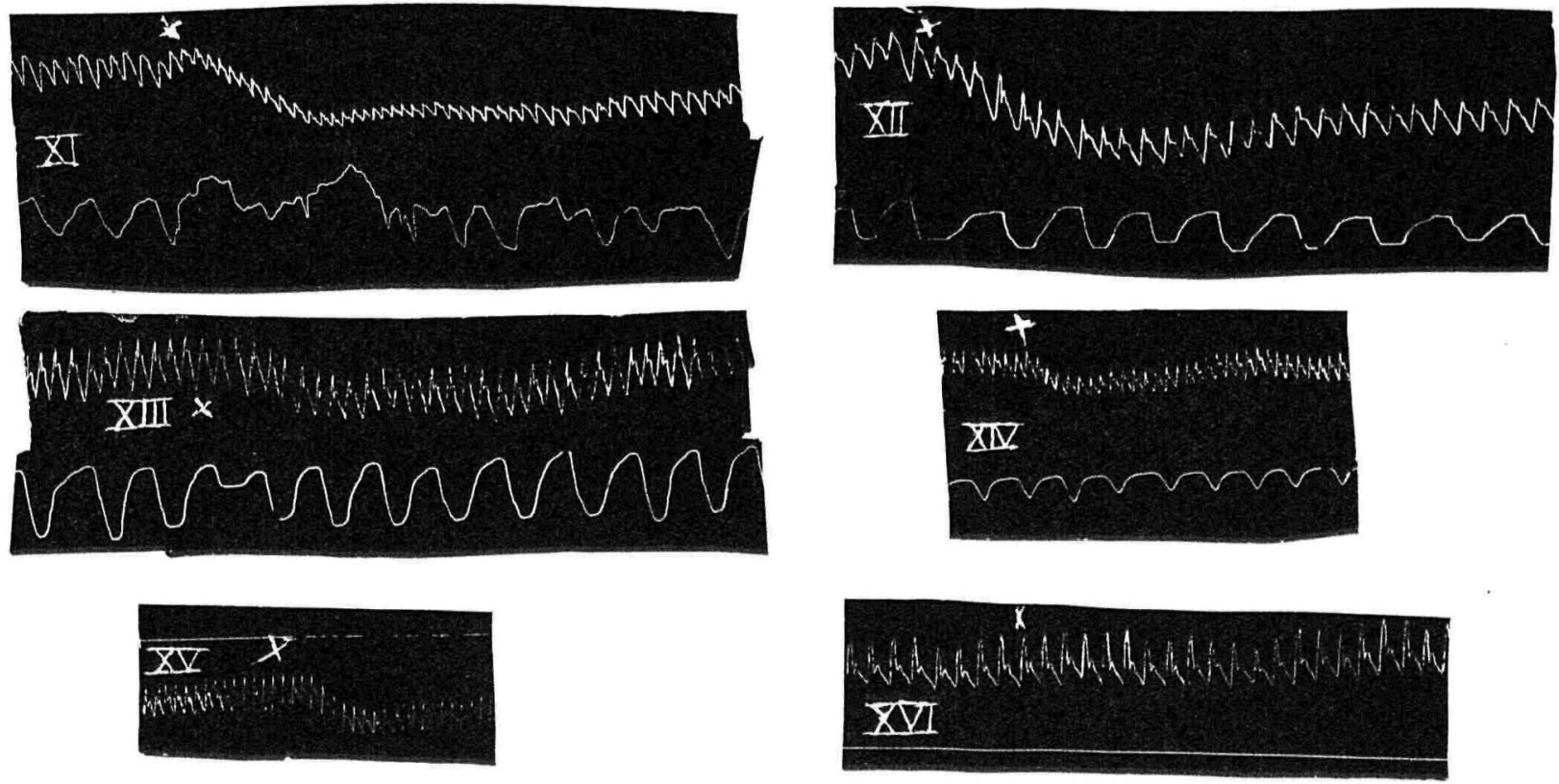

XI., Cold; XII., Noise; XIII., Camphor; XIV., Cold; XV., Noise; XVI., Camphor. 
decrease for both subjects in almost all of the emotional experiences, whether agreeable or disagreeable. There were, however, a few cases of increase of amplitude. The great irregularity of amplitude during emotional experiences is a more uniform factor. (See Figs. I., II., III. and IX.) The rate of the heart-beat is sometimes increased on an average, sometimes decreased, and sometimes not changed at all. Increase of rate is much the most frequent occurrence regardless of the quality of the emotion, but all of these changes take place during each of the two great emotional states (compare Figs. I., rate unchanged; II., rate increased ; III, rate both increased and decreased ; and X., rate decreased). But whatever the average change of rate may be, a more uniform and, in our opinion, more significant feature is the spasmodic irregularities of the rate characteristic of curves corresponding to emotional states (compare Figs. I., II., III., IV., $V$. and $X$.), a feature strongly indicative of the general physiological instability of emotional states for which we are contending. The changes in form and position of the dicrotic notch ${ }^{1}$ are as erratic as the amplitude and rate changes. The notch is sometimes raised, sometimes lowered, sometimes emphasized and sometimes flattened, with entire disregard to the affective tone of the emotion.

The breathing during emotional experiences shows no greater uniformity in direction of change than the pulse. All the variations of increase and decrease of both rate and amplitude of the breathing are found accompanying both agreeable and disagreeable experiences. In the more violent emotions (see Figs. I. and II.), and, of course, in laughter, the breathing becomes very spasmodic and irregular as to both rate and amplitude. The lesser emotions show smaller disturbances (see Figs. IV., and $X$. ), while some of them show no change at all (see Fig.

1 The emphasis and position of the dicrotic notch vary greatly in our different curves. This is no donbt largely due to the fact that the dicrotic notch varies so greatly at different times of the day and under different conditions of nutrition and of activity. (See Binet and Courtier, L'Année Psychologique, 1897, p. Io.) It may also be due in part to slight differences in the adjustment of the instruments at various sittings. But, since our conclusions are based upon immediately successive changes in the form of the curve only, this is a matter of no moment in the present case. 
Plate V.

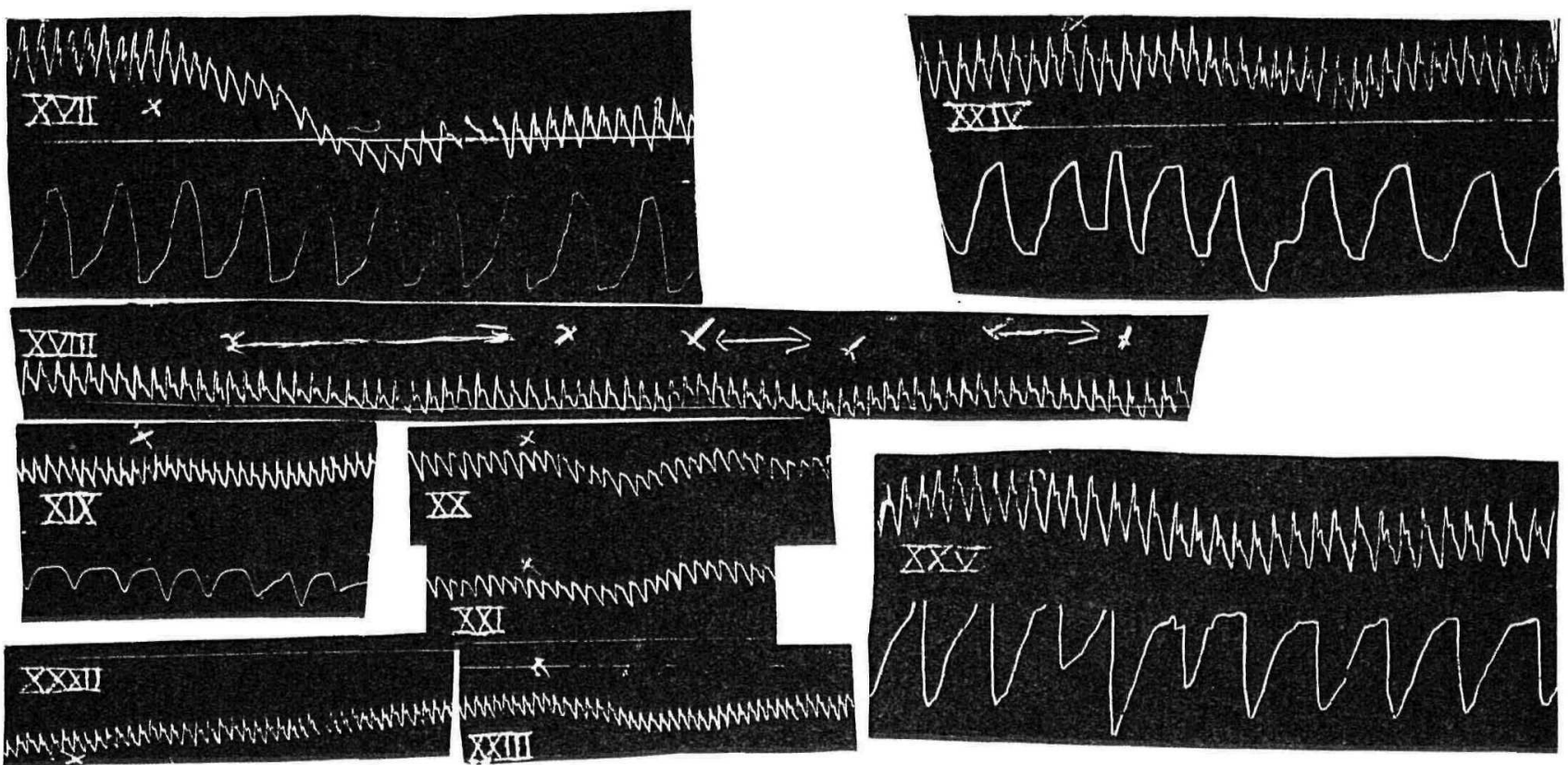

XVII., Heat; XVIII., Color red, eyes open where arrows occur; XIX., Expected noise; XX., Slight noise; XXI., Cold; XXII., XXIII., Disagreeable odor, capsicum; XXIV., XXV., Camphor. 
IX). The breathing, then, at least in the case of the more violent emotions, shows the same functional disturbance which has already been shown to be characteristic of the pulse curves.

According to the psychological analysis of the states known as emotion, sensation and intellectual application, which was offered in the preceding section, we found that, when classified with respect to the stability of the attentive process involved, sensation occupies a middle range between emotion and mental application. It was also pointed out that the term sensation covers a great variety of experiences, some of which border closely upon emotional states, while others approach the intellective conditions. If the hypothesis is correct, that the degree of stability of the physiological processes runs parallel with the degree of stability in the attentive process, we ought to find in general the curves for sensation showing less disturbance than those for emotional states, and more than the curves for intellectual application. Moreover, we ought to find the curves representing sensation varying from curves approaching the emotional type to those closely resembling the type of intellectual application, according to the quality of the sensation as regards the functioning of attention. This is exactly the relationship which a study of our curves reveals.

Figs. XI. to XVI., inclusive, are typical curves of sensory stimulation. The first three of the set are taken from one subject, and the last three from the other. A comparison of these curves with the preceding ones of emotional experiences and with the succeeding curves of mental application (Figs. XXVI. to XXXI.) will show that the vaso-motor shifts for sensory stimuli are not so great as those for emotional experiences, but are much greater than those in the mental application curves. The amplitude and rate are less spasmodic and irregular than those for emotional states, but not nearly so uniform and even as the rates and amplitudes of the curves of mental application. The amplitude and rate changes which occur are often equal in amount to those of emotional experiences, but they are less jerky and irregular. They approach more nearly the even, progressive changes of mental application.

But within the large class of psychic states known as sensa- 

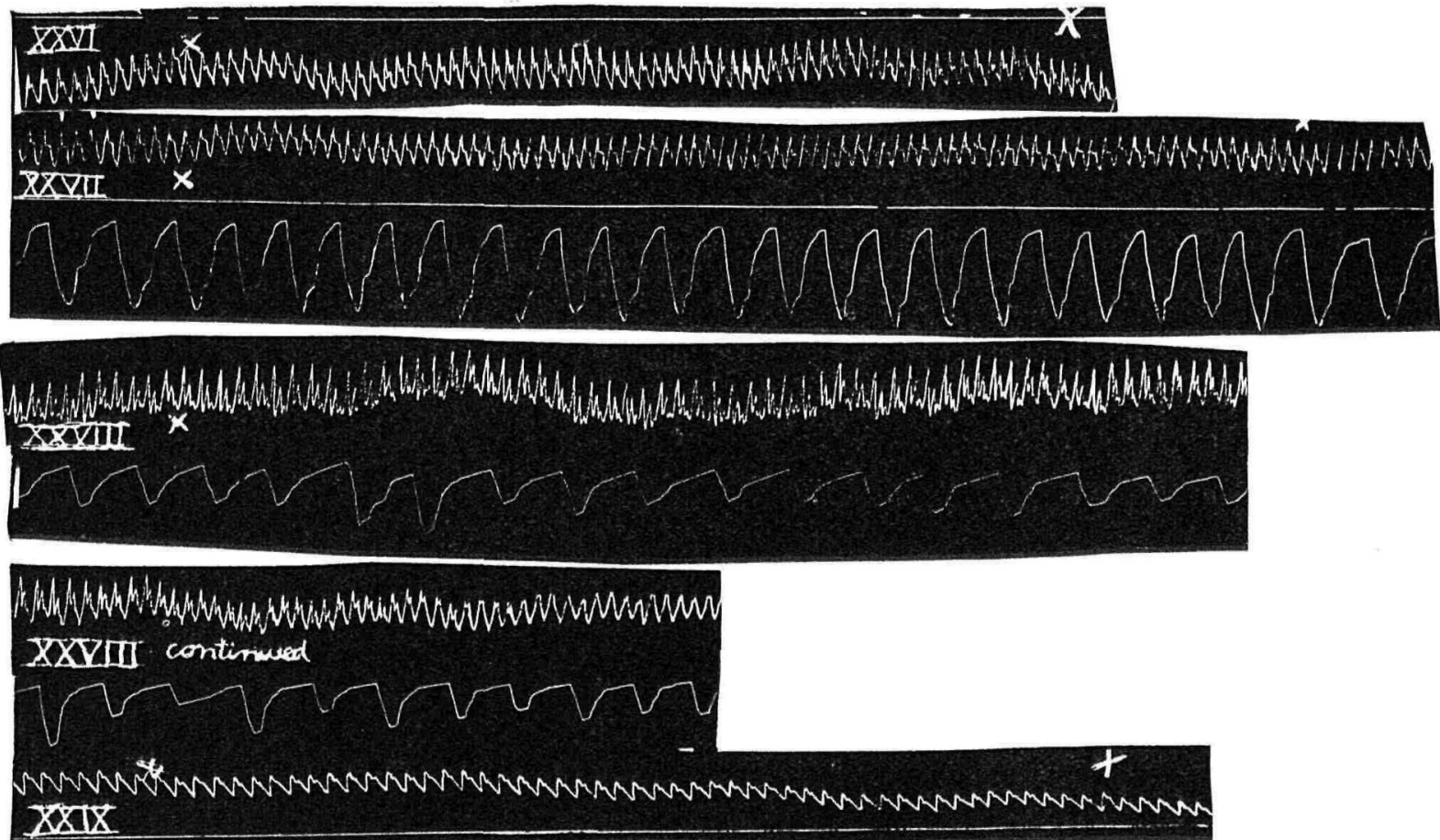
tion, for which the statements in the preceding paragraph are true in general, we find the wide variations in the accompanying bodily processes which our psychological analysis has led us to expect. Various sensory stimuli produce experiences of widely different intensities. A hot object touching the skin produces a much more intense experience than a colored light impinging on the retina, and, therefore, makes a much more imperative demand for attention. The shift from the preceding state to the new experience is much more sudden and violent in the case of the hot stimulus, and involves a rudimentary shock, which is entirely lacking in the color stimulation. The different bodily processes accompanying these two sensations are shown in Figs. XVII. and XVIII. The sudden violent changes in vaso-motor level accompanying the heat stimulus are much like those of the emotional experiences, while the slight gentle fluctuations of the color experience approach the mental application curves.

But even the same kind of sensory stimulus occasions states which differ greatly in intensity at various times, according to the actual physical intensity of the stimulus, the nervous irritability of the subject at the moment when the stimulus occurs, and the element of surprise involved, A loud noise, for instance, produces a much greater shock, and a correspondingly greater disturbance in the bodily processes, when it is unexpected than it does when the subject is prepared for it. Fig. XV. shows the effects of an unexpected noise. Fig. XIX. is a curve for noise taken at the same sitting, with the sole difference that in Fig. XIX. the noise was expected. The shock involved in the unexpected noise made the experience take on an emotional tone, which is reflected in the spasmodic change of vaso-motor level and amplitude, while the expected noise produces only a slight irregularity in the curve. When both noises are unexpected, a loud noise produces a much more violent shift of attention than a slight one. Fig. XII. is a characteristic curve for a loud noise, while Fig. XX. shows the effect of a slight noise upon the same subject. The contrast is much the same as that between the expected noise and the unexpected one. Furthermore, a stimulus which occurs while the subject is 
Plate VII.

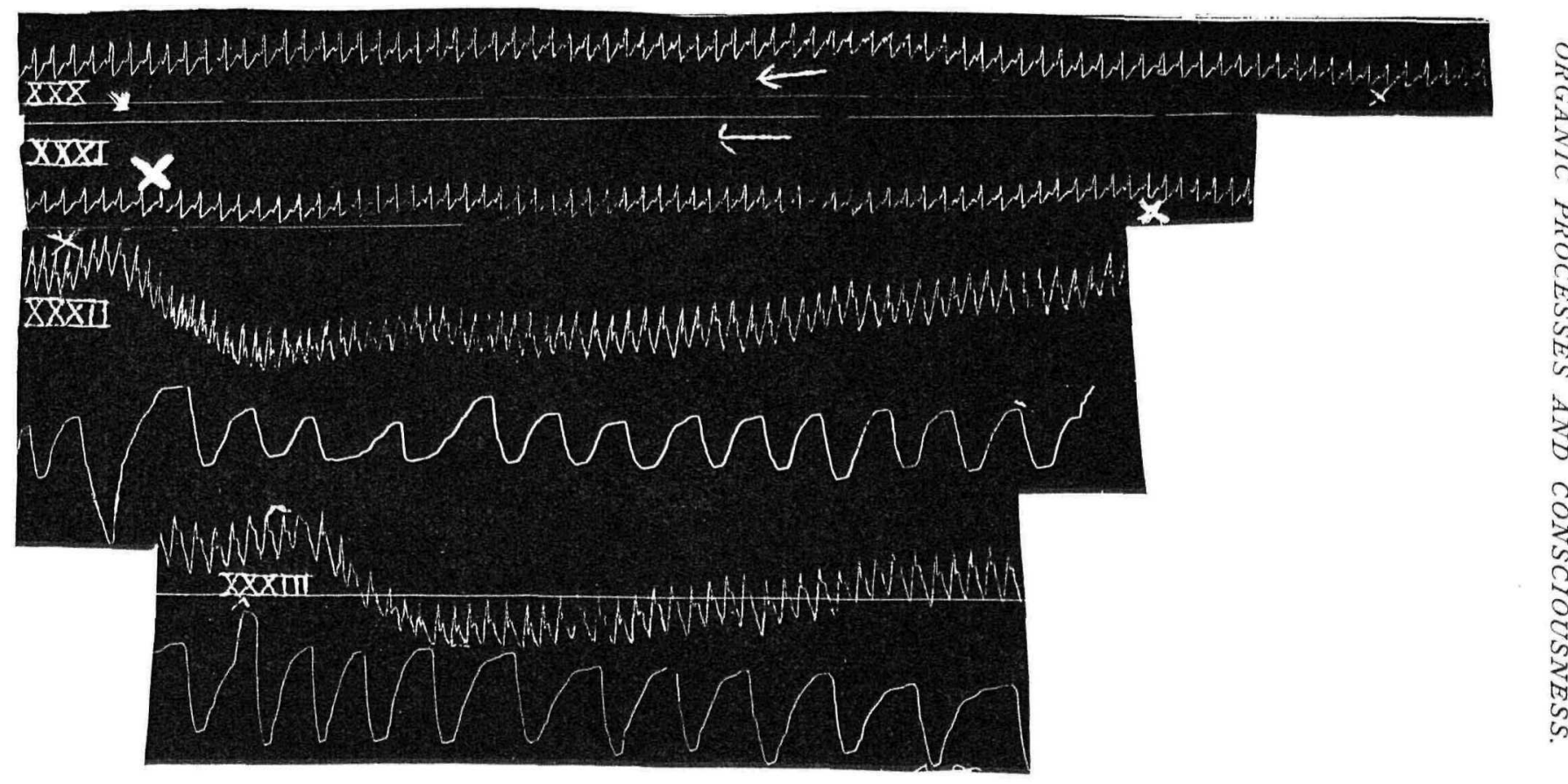

XXX., Addition; XXXI., Multiplication; XXXII, Emotion, thought of friend's illness; XXXIII, Noise. 
64 J. R. ANGELL AND H. B. THOMPSON.

Plate ViII.

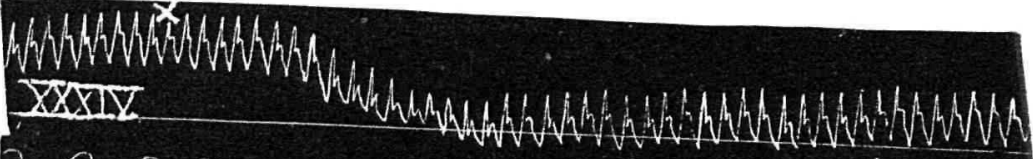

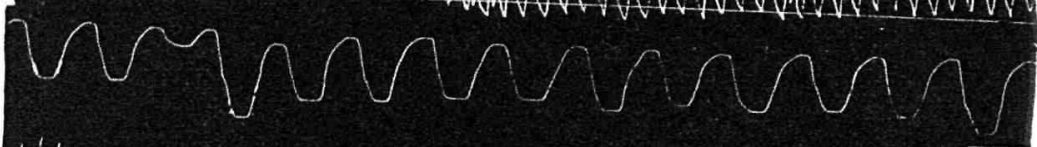

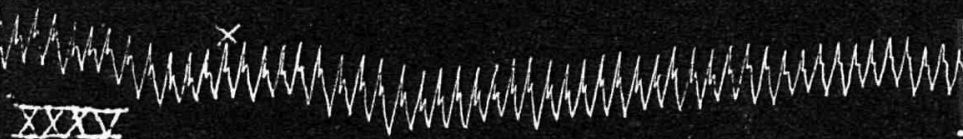

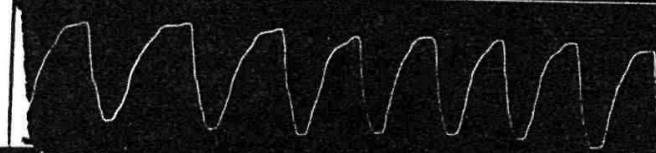

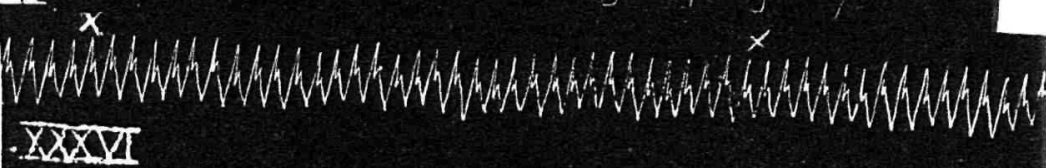

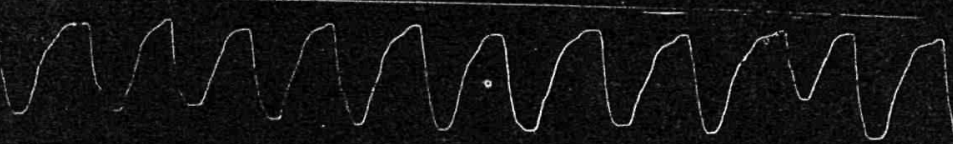

XXख्या

$x$

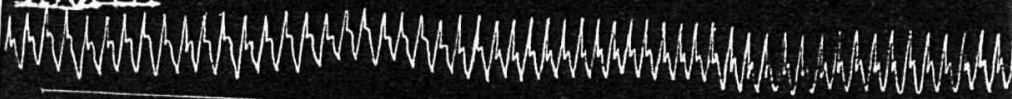

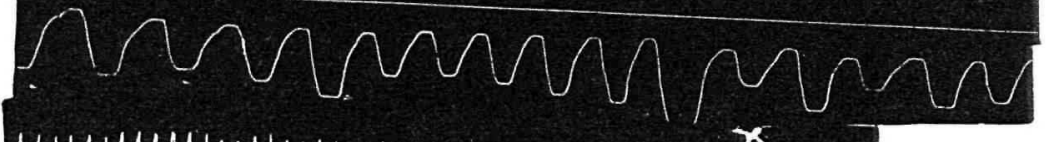

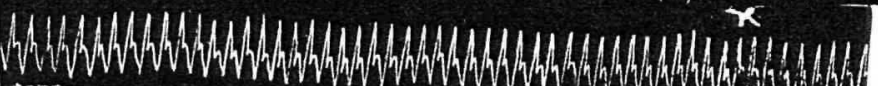

Xregl corntimsed

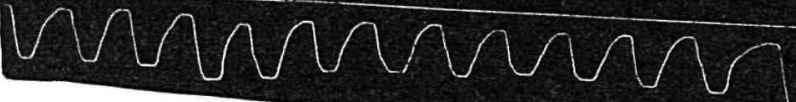

XXXIV., Capsicum ; XXXV., Knocking; XXXVI., Cross I, Camphor; Cross 2, Rubber Cement; XXXVII., Addition. 
nervously excited produces a muc hmore disturbing effect, and makes the readjustment of attention a much more difficult matter, than the same stimulus would if the subject were calm. Fig. XI. is the curve of a cold stimulus which occurred during a state of emotional excitement. Fig. XXI. is also the curve of a cold stimulus, given at the same sitting, but at a time when the subject was calm. The difference in the effect of the two stimuli is entirely disproportionate to the slight difference there may have been between the absolute intensities of the two.

The breathiner luring sensory stimulations undergoes irregular changes in räte and amplitude, more or less analogous to those of the pulse. An experience intense enough to cause a profound change in one usually shows itself in the other also (see Fig. XI.). When the experience is less intense it sometimes produces an effect on the pulse curve, but none on the breathing, although the reverse seldom happens. On the whole, the breathing in cases of sensory stimulations is characterized by slight spasmodic irregularities, usually of short duration (Figs. XI., XII., XIII., XIV., XXV.). With the weaker and less effective stimuli these are often lacking, and sometimes fail even with the more intense experiences (see Fig. XVII.). As compared with emotional states, the disturbances of the breathing during sensory stimulation are of less frequent occurrence and of briefer duration.

The search for uniformity in classes or kinds of sensory stimuli is as fruitless as it proved to be in the emotional states. An overwhelming majority of sensory stimuli of all kinds, whether agreeable or disagreeable, caused vaso-constrictions. The few cases of pronounced vaso-dilation do not correspond to the distinctly pleasant stimuli. The most distinctly pleasurable stimulus used, harmony, caused constrictions on all of the few occasions when it was given. Unpleasant odors, such as camphor and capsicum, caused dilations on a few occasions. Figs. XXII. and XXIII. are the curves for two disagreeable odors, both capsicum, given within a few minutes of each other to the same subject. As the curves show, one caused a slight dilation and the other a somewhat greater constriction.

The amplitude changes of the pulse curve show no greater 
constancy in the direction of change for different kinds of stimuli than does the vaso-motor level. There is a great preponderance of decreases of amplitude over increases for sensory stimuli as a whole, but here again there seems to be no particular significance in the direction of the change for different experiences. For instance, disagreeable odors cause sometimes increase and sometimes decrease of amplitude (see Figs. XXII. and XXIII.). Cold is sometimes accompanied by a decrease of amplitude (Figs. XI. and XIV.) and sometimes by increase (Fig. XXI.). The relatively few cases of harmony among our tests all produced an increase of the amplitude of the pulse curve, a fact which suggests increase of amplitude as a correlate of pleasant experiences, until we notice that discords have the same effect.

The rate changes of the heart-beat during sensory stimulations are about equally divided between increases and decreases. Cold, noise, odors-in fact, all the stimuli of which we have any considerable number of tests-cause sometimes one and sometimes the other in a manner which, on present data, is entirely erratic. The cold stimulation shown in Fig. XIV. causes a slight temporary decrease of the pulse rate, while that of Fig. XI. is accompanied by a progressive increase. Figs. XXIV. and $\mathrm{XXV}$. show the curves for two camphor stimulations, the first of which causes an increase of pulse rate and the second a decrease.

The dicrotic notch changes its emphasis and its position with reference to the apex of the pulse curve with as little regard to the nature of the stimulus as is shown by the other factors. With one subject the dicrotic, when it suffers any change at all, undergoes an almost uniform flattening during sensory stimuli of all kinds. With the other subject it is emphasized almost as often as it is flattened. The position of the dicrotic remains unchanged during the great majority of sensory stimuli for both subjects. When it is raised or lowered it happens apparently without reference to the nature of the stimulus.

The mental application tests used were chiefly simple arithmetical problems given as fast as the subject could perform them. In a few cases the memorizing of a series of nonsense syllables was employed. The curves of mental application are characterized by the slight amount of the vaso-motor changes involved, and 
by the even progression in which changes in rate and amplitude take place, when they occur at all. The vaso-motor level usually shows slight fluctuations, although they are always less than the fluctuations of revery for the same day. Frequently the changes are so slight as to be scarcely noticeable (Figs. XXVI., XXVII. and XXVIII.). The respiratory rhythms disappear.

The breathing is more regular in most cases, although there are some exceptions. In memorizing nonsense syllables the breathing curve is broken up by a tendency to pronounce the syllables. In some cases of mental application, such as Fig. XXXVII. there are occasional irregularities. The fact that the breathing is under voluntary control, and that it is immediately affected by any tendency to use motor images of words, would lead us to expect that the uniformities would be less evident in that case than in the case of the purely reflex vaso-motor phenomena. As compared with emotional experiences and with sensory stimulations, and even with revery, the bodily processes accompanying mental application are characterized by greater stability and regularity. If our psychological analysis is correct, mental application is a state in which the attentive process is most stable, runs most smoothly and offers greatest resistance to change. Here, again, the correspondence between the degree of stability of the attentive process and the degree of stability of the accompanying bodily processes holds.

But as in the former cases, so in mental application, the direction of the various changes which do occur, offers no basis of classification which articulates with the psychological classification, either into intellective as opposed to affective states, or into agreeable as opposed to disagreeable states. The subjects found no distinctly affective tone in the various mental application tests used. Since no psychological classification on the basis of agreeable and disagreeable is possible in this case, it would be absurd to intrepret the vasodilations and constrictions as having such a significance. If the direction of the changes characterized intellective states as opposed to affective states we ought, of course, to expect to find some uniformity in the direction of change of mental application tests as a whole. But this is entirely lacking. In almost half 
of the mental application tests the vaso-motor level shows both dilations and constrictions within a single test (Figs. XXVI., XXVII. and XXVIII.). Where the vaso-motor level changes in only one direction it seems to be an even chance whether it shall be a dilation or a constriction. Frequently there is no change of level. Fig. XXIX. illustrates a mental application test where there is only constriction and Fig. XXXVII. one where there is only dilation.

The amplitude of the pulse curve in mental application shows a greater tendency to decrease than to increase. In all of the few tests made, which exceeded two minutes in time, there was a marked decrease of amplitude at the end, even when there was an increase at the beginning. But among the tests of shorter duration there were several where the amplitude increased without any subsequent decrease. The pulse rate of mental application shows a greater tendency to increase than to decrease, but the cases of decrease of rate, although less numerous than those of increase, are frequent. ${ }^{1}$ But, whatever the direction of the change, it takes place slowly and gradually. (See Fig. XXXVII. for increase of pulse rate and Fig. XXXI. for decrease of rate.)

The rate and amplitude of the breathing curves change in contrary directions during mental application in quite as erratic a manner as the pulse curves. ${ }^{2}$ One subject shows an almost uniform increase of breathing rate, while the other has a few more cases of decrease than of increase. With both subjects the amplitude is more often decreased than increased, but there are frequent cases of increase. (See Fig. XXVII. for increase of breathing amplitude and Fig. XXXVII. for decrease.)

As a summary of the results of these experiments, we can offer nothing better than a series of tests illustrating each of the different types of processes from curves obtained at a single sitting of about an hour's duration. There is first the emotional experience of the sudden thought of a friend's illness (Fig. XXXII.),

${ }^{1}$ Most investigators report much greater constancy in the cases of increase of rate in the heart under these conditions. Certaınly it is the most usual occurrence.

${ }^{2} \mathrm{MacD}$ ougall and the French writers report increase in rate and decrease in amplitude as constant. Delabarre's observations suggest a considerable difference in individuals in this respect. 
with its marked fall in vaso-motor level and its irregularity in all the features of pulse and breathing curves. Next comes the startling noise (Fig. XXXIII.), which involves as sudden and violent a shift of attention as the emotion and produces a very similar curve. Next in order is a disagreeable and annoying odor-capsicum (Fig. XXXIV.). In this case the vaso-motor fall is less, though still very evident, and irregularities in amplitude and rate are decreased. The slight disturbance caused by an unexpected knock at the laboratory door, makes still less of a fall in vaso-motor level, but yet shows other irregularities (Fig. XXXV.). The odors of camphor and rubber cement, which were not at all annoying unless strong, produce no marked change in the curve (Fig. XXXVI.). The slight shifts of vasomotor level, and slight irregularities of rate and amplitude, resemble closely those of the preceding state of revery. No strong demand for attention is made by them. Finally, mental application (Fig. XXXVII.) produces a steady strain of attention, which is accompanied by a curve practically devoid of fluctuations in vaso-motor level, with an amplitude which is almost constant, and a slowly, progressively increasing rate.

All the processes with which we have been dealing are cases of readjustment of an organism to its environment. Attention is always occupied with the point in consciousness at which the readjustment is taking place. If the process of readjustment goes smoothly and evenly, we have a steady strain of attention -an equilibrated motion in one direction. The performance of mental calculation is a typical case of this sort of attention. But often the readjustment is more difficult. Factors are introduced which at first refuse to be reconciled with the rest of the conscious content. The attentive equilibrium is upset, and there are violent shifts back and forth as it seeks to recover itself. These are the cases of violent emotion. Between these two extremes comes every shade of difficulty in the readjustment, and of consequent intensity in emotional tone. We have attempted to show in the preceding paper that the readjustment of organism to environment involves a maintenance of the equilibrium of the bodily processes, which runs parallel with the maintenance of the attentive equilibrium, and is an essential part of the readjustment of the psychophysical organism. 